\title{
Impaired Verbal Category Learning in Amnesia
}

\author{
Erin G. Kitchener \\ University of California, San Diego
}

\author{
Larry R. Squire \\ Veterans Affairs Medical Center, San Diego, \\ and University of California, San Diego
}

\begin{abstract}
Amnesic patients and controls listened to verbal descriptions of imaginary animals and then classified novel descriptions according to whether they belonged to the studied category. Controls performed well, but the amnesic patients did not acquire categorical knowledge. These findings contrast with previous demonstrations of intact category learning by amnesic patients for dot patterns, artificial grammars, and cartoon animals. It appears that category knowledge can be acquired implicitly when training exemplars are presented visually and when the similarities among items can be readily perceived. Verbal category learning requires the extraction and retention of meaning from training exemplars that are separated in time and may make demands on declarative memory that are beyond the capacity of amnesic patients.
\end{abstract}

Memory is not a unitary function but is composed of a number of dissociable systems. The main distinction is between the capacity for declarative memory, which depends on medial temporal and diencephalic structures and supports conscious recollections of facts and events; and nondeclarative memory, which is composed of several nonconscious learning abilities that are independent of medial temporal lobe structures (Schacter, Chiu, \& Ochsner, 1993; Schacter \& Tulving, 1994; Squire, 1992). Amnesic patients with medial temporal or diencephalic lesions have impaired declarative memory. However, the same patients exhibit normal performance on many tasks of skill learning and habit learning, and they exhibit intact priming.

Recent studies have shown that amnesic patients can learn to classify visual stimuli according to whether or not they belong to a trained category. For example, following the presentation of a series of dot patterns that are distortions of an unstudied prototype, amnesic patients performed as well as controls at judging whether or not novel dot patterns belonged to the same category as the training patterns (Knowlton \& Squire, 1993; Squire \& Knowlton, 1995). The patients, however, were severely impaired at recognizing which patterns had been studied. Thus, it appears that at least some kinds of category learning can occur implicitly, despite severely impaired declarative memory.

More recently, it was found that amnesic patients could also learn to classify when the training stimuli (cartoon animals) were

Erin G. Kitchener, School of Medicine, University of California, San Diego; Larry R. Squire, Medical Research Service, Veterans Affairs Medical Center, San Diego, and School of Medicine, University of California, San Diego.

This work was supported by the Medical Research Service of the Department of Veterans Affairs and by National Institutes of Health Grant MH24600. We thank James Moore and Joyce Zouzounis for research assistance.

Correspondence concerning this article should be addressed to Larry $\mathrm{R}$. Squire, Veterans Affairs Medical Center 116A, 3350 La Jolla Village Drive, San Diego, California 92161. Electronic mail may be sent to lsquire@ucsd.edu. composed of discrete features and were easy to verbalize (Reed, Squire, Smith, Jonides, \& Patalano, 1999). The amnesic patients were as good as controls at categorizing the animals, although they were markedly impaired on a test of declarative memory that asked about the features that had been used to construct the animals.

In the present study we asked whether amnesic patients can also accomplish category learning when the study items are discrete items presented verbally. The ability to acquire category information from verbally presented descriptions has not been studied previously in amnesic patients. We were interested in whether category learning can occur nondeclaratively when discrete items of information are presented verbally or whether verbal presentation creates demands on declarative memory such that amnesic patients cannot learn. Participants first studied a series of twofeature verbal descriptions of imaginary animals and then classified novel verbal descriptions according to whether or not they belonged to the same category as the study items.

\section{Method}

\section{Participants}

Amnesic patients. Six amnesic patients were studied, 4 men and 2 women. Three patients (J.W., P.N., and M.H.) have Korsakoff's Syndrome. J.W. and P.N. had participated in quantitative imaging studies, which demonstrated reductions in the volume of the mammillary nuclei, decreased tissue density within the thalamus, and frontal lobe atrophy (Shimamura, Jernigan, \& Squire, 1988; Squire, Amaral, \& Press, 1990). Of the other 3 patients, 2 (P.H. and L.J.) have bilateral damage to the hippocampal formation as demonstrated by magnetic resonance imaging (MRI; Polich $\&$ Squire, 1993; Reed \& Squire, 1998). P.H. had a 6-year history of brief (possibly epileptogenic) attacks, in association with gastric symptoms and transient memory impairment. In July 1989, he suffered a series of these episodes that resulted in severe memory impairment. L.J. became amnesic gradually during a 6-month period in 1988. Her memory impairment has been stable since that time. Finally, A.B. became amnesic in 1975 following an anoxic episode associated with cardiac arrest. He is ineligible for MRI studies because he wears a pacemaker, but it is assumed that he has hippocampal damage on the basis of his etiology. Background information and neuropsychological data for all 6 amnesic patients are shown in Tables 1 and 2 . 
Table 1

Characteristics of Amnesic Patients

\begin{tabular}{|c|c|c|c|c|c|c|c|c|}
\hline \multirow[b]{2}{*}{ Patient } & \multirow{2}{*}{$\begin{array}{c}\text { Year } \\
\text { of } \\
\text { birth }\end{array}$} & \multirow{2}{*}{$\begin{array}{c}\text { Education } \\
\text { (years) }\end{array}$} & \multirow[b]{2}{*}{ WAIS-R IQ } & \multicolumn{5}{|c|}{ WMS-R } \\
\hline & & & & Attention & Verbal & Visual & General & Delay \\
\hline A.B. & 1937 & 20 & 104 & 87 & 62 & 72 & 54 & $<50$ \\
\hline L.J. & 1937 & 12 & 98 & 105 & 83 & 60 & 69 & $<50$ \\
\hline M.H. & 1947 & 16 & 101 & 77 & 73 & 80 & 69 & 60 \\
\hline P.H. & 1922 & 19 & 120 & 117 & 67 & 83 & 70 & 57 \\
\hline P.N. & 1927 & 11 & 99 & 81 & 77 & 73 & 67 & 53 \\
\hline J.W. & 1936 & 14 & 98 & 104 & 65 & 70 & 57 & 57 \\
\hline$M$ & & 15.3 & 103.3 & 95.2 & 71.2 & 73.0 & 64.3 & 54.5 \\
\hline
\end{tabular}

Note. The Wechsler Adult Intelligence Scale-Revised (WAIS-R) and the Wechsler Memory Scale-Revised (WMS-R) yield mean scores in the normal population of 100 and a standard deviation of 15 . The WMS-R does not provide scores for individuals scoring below 50, and a score of 50 was used in these cases for computing a group mean.

Healthy volunteers. These 8 women were volunteers or employees at the San Diego Veterans Affairs Medical Center. As a group, they averaged 68.6 years of age and 15.3 years of education. They obtained mean scores of 24.5 and 62.6, respectively, on the Information and Vocabulary subscales of the Wechsler Adult Intelligence Scale-Revised (WAIS-R; compared with 21.7 and 55.2, respectively, for the amnesic patients).

\section{Materials and Procedure}

During the first phase of the experiment, participants were presented with a series of 80 verbal descriptions of imaginary animals. Each description involved two features, for example, "This animal has paws and has a long tail" or "This animal has antlers and has pointed ears." The 80 two-feature descriptions were read aloud at a pace of about one item every $3 \mathrm{~s}$ with a 3-s inter-item interval. Participants were instructed to listen carefully to each item and to try to imagine what each animal would look like. The entire study session required about $10 \mathrm{~min}$.
In all, there were eight different features, and each feature could have either the prototypic or the nonprototypic value (see Table 3). The 80 training items were derived from 20 eight-feature verbal descriptions of imaginary animals, constructed such that each description consisted of 6 prototypic and 2 nonprototypic features. The 20 eight-feature descriptions were then divided into 80 two-feature training items, with the constraint that no item contained only nonprototypic features. Forty of the training items contained two prototypic features, and 40 contained one prototypic and one neutral feature. Each feature was assigned the prototypic value for 15 of the 20 items in which it appeared.

Immediately following the study phase, participants were told that all of the study items described animals belonging to the same category; they were all a type of animal called a Veggle. The concept of category membership was then explained, and participants were told that they would next be read descriptions of new animals and that their task would be to decide whether or not each new animal was a Veggle. They were also told that approximately half of the new animals would be Veggles and that they

Table 2

Performance of the Amnesic Patients on Standard Memory Tests

\begin{tabular}{|c|c|c|c|c|c|c|c|c|}
\hline \multirow[b]{2}{*}{ Participant } & \multirow{2}{*}{$\begin{array}{l}\text { Diagram } \\
\text { recall }\end{array}$} & \multicolumn{3}{|c|}{ Paired associates trial } & \multirow{2}{*}{$\begin{array}{l}\text { Word recall } \\
(\%)\end{array}$} & \multirow{2}{*}{$\begin{array}{c}\text { Word } \\
\text { recognition }(\%)\end{array}$} & \multirow[b]{2}{*}{50 words } & \multirow[b]{2}{*}{50 faces } \\
\hline & & 1 & 2 & 3 & & & & \\
\hline \multicolumn{9}{|l|}{ Patient } \\
\hline A.B. & 4 & 1 & 1 & 1 & 33 & 83 & 32 & 33 \\
\hline L.J. & 3 & 0 & 0 & 0 & 40 & 93 & 33 & 29 \\
\hline M.H. & 4 & 0 & 3 & 2 & 35 & 72 & 27 & 29 \\
\hline P.H. & 3 & 0 & 0 & 1 & 27 & 84 & 36 & 34 \\
\hline P.N. & 2 & 1 & 1 & 1 & 29 & 83 & 31 & 31 \\
\hline J.W. & 4 & 0 & 0 & 2 & 28 & 96 & 29 & 34 \\
\hline$M$ & 3.3 & 0.3 & 0.8 & 1.2 & 32.0 & 85.2 & 31.3 & 31.7 \\
\hline \multicolumn{9}{|l|}{$\begin{array}{l}\text { Controls } \\
\quad(n=8)\end{array}$} \\
\hline$M$ & 20.6 & 6.0 & 7.6 & 8.9 & 71 & 97 & 41.1 & 38.1 \\
\hline
\end{tabular}

Note. The diagram recall score is based on the delayed (12-min) reproduction of the Rey-Osterreith Complex Figure (Osterreith, 1944; maximum score = 36). For copying the figure, the amnesic group obtained normal scores (Kritchevsky, Squire, \& Zouzounis, 1988). The paired associates score is the number of word pairs recalled on three successive trials (maximum score $=10 /$ trial). The word recall score is the mean percentage of 15 words recalled across five successive study-test trials (Rey, 1964). The word recognition score is the mean percentage of words identified correctly across five successive study-test trials (yes-no recognition of 15 new words and 15 old words). Note that scores on the recall test are above zero because on this test of immediate recall, several items can be retrieved from immediate memory, which is intact in amnesia. The scores for words and faces are based on a 24-hr recognition test of 50 words and 50 faces (modified from Warrington, 1984; maximum score $=50$, chance $=25$ ). The mean scores for the controls are from Squire and Shimamura (1986) 
Table 3

Descriptions of the Feature Values of the Imaginary Animals

\begin{tabular}{lcc}
\hline \multicolumn{1}{c}{ Feature } & Prototypic value & Nonprototypic value \\
\hline Ears & Pointed & Floppy \\
Color & Brown & White \\
Markings & Stripes & Spots \\
Hair length & Long & Short \\
Hair type & Straight & Curly \\
Head ornament & Antlers & Horns \\
Feet & Hooves & Paws \\
Tail & Long & Short \\
\hline
\end{tabular}

should not base their decisions on a single feature but rather on the overall description of each animal.

Participants then performed a categorization task involving 60 novel items, each containing four features. Each item was read aloud by the experimenter, and participants made a yes-no decision for each item. There were three types of items: 12 prototypical items (all of the four features were prototypic), 24 low-distortion items (three of the four features were prototypic), and 24 neutral items (two of the four features were prototypic). The three item types were randomly ordered in the test, with the constraint that no item type occurred on three or more successive trials.

At the conclusion of the categorization task, a recognition test of the prototypic feature values was given. Participants were read the prototypic and nonprototypic values for each of the eight features and asked to decide in each case which was most typical of the Veggles that they had heard about.

\section{Results}

Figure 1 shows the categorization performance of amnesic patients and controls. The data were scored according to how often each of the three item types was endorsed. Overall endorsement rate was similar for the amnesic patients $(M=56.4 \%)$ and controls $(M=52.9 \%), t(12)=0.57, p>.10$. A $2 \times 3$ analysis of variance (ANOVA) revealed a main effect of item type (prototype, low distortion, neutral), $F(2,24)=6.28, p<.01$, but no effect of group (amnesic, control), $F(1,12)=0.1, p>.10$. There was a marginally significant interaction between item type and group, $F(2,24)=3.06, p<.07$, reflecting the different patterns of endorsement within each group. Separate analyses showed that item type had a significant effect on performance in the control group, $F(2,14)=7.34, p<.01$, but not in the amnesic group, $F(2$, $10)=1.99, p>.10$. Thus, the performance of the controls indicated that they had learned about the trained category. The amnesic patients did not learn the category.

Categorization performance was also scored by determining the total number of correct categorization responses. In the case of prototypical items and low-distortion items, a correct response was scored when the test item was endorsed. In the case of the neutral items, a correct response was scored when the test item was not endorsed. By this measure, the controls scored $60.0 \%$ correct, significantly better than the $50.3 \%$ score of the amnesic patients, $t(12)=2.3, p<.05$.

In studies of category learning, the test phase typically consists of a large number of items that either belong or do not belong to the trained category. Palmeri and Flannery (1999) suggested that acquisition of categorical knowledge may occur during the test phase, because individuals may notice that some of the test items resemble each other. In the present study, the categorical learning exhibited by the controls clearly depended on the study phase, because category knowledge was evident in the earliest trials of the test (after five test trials: prototypic items $=75.0 \%$ endorsement, low-distortion items $=62.5 \%$ endorsement, and neutral items $=37.5 \%$ endorsement).

Inspection of individual data indicated that 6 of the 8 controls performed as would be expected if category learning had occurred. That is, these 6 controls endorsed a larger percentage of prototypic items than low-distortion items and also endorsed more lowdistortion items than neutral items. In contrast, within the amnesic group only 1 patient exhibited this pattern of performance. The individual data further suggested that controls learned about the studied category and did not base their judgments on only a single feature of the test items. None of the controls endorsed any of the prototypical features $100 \%$ of the time (which would have occurred if judgments were based on the presence or absence of a single feature). Indeed, the average endorsement rate across all the controls for the most frequently endorsed feature was well below $100 \%(M=75.4 \%$, range $=55-85 \%)$.

Consistent with their impairment in declarative memory, the amnesic patients did not perform above chance on the recognition test of prototypic feature values $(66.7 \% \pm 8.9), t(5)=1.87$, $p>$.1. Controls obtained a recognition score of $85.9 \%$, well above chance, $t(7)=7.22, p<.01$, and marginally better than that of the amnesic patients, $t(12)=2.01, p=.067$.

In summary, whereas controls performed well on the verbal categorization task, the amnesic patients did not acquire categorical knowledge. The amnesic patients also were poor at recognizing the prototypic features of the training items.

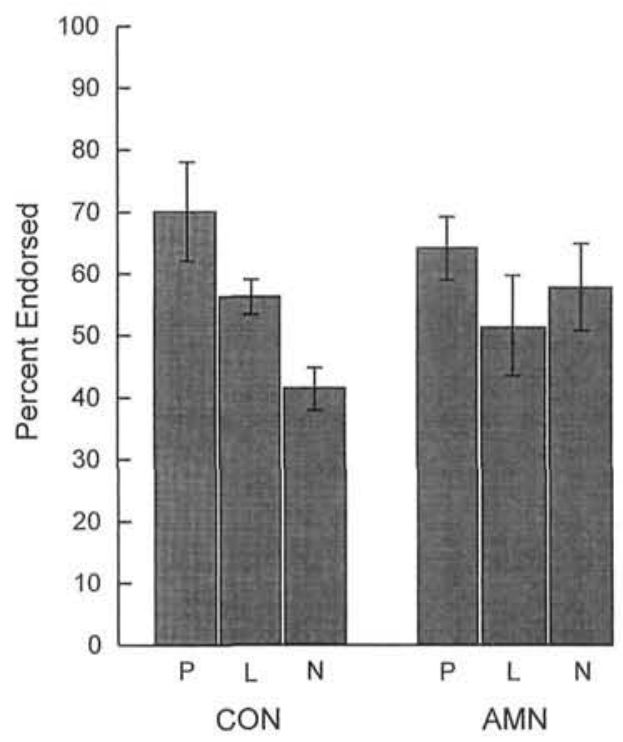

Figure 1. Categorization test performance of 6 amnesic patients (AMN) and 8 controls (CON). The three item types are defined by the number of prototypic features they contain. For prototypical items (P), all four features were prototypical. For low-distortion items (L), three of the four features were prototypical. For neutral items $(\mathrm{N})$, two of the four features were prototypical. Error bars show standard errors of the means. 


\section{Discussion}

We report the first study of verbal classification learning in amnesia. Participants listened to verbal descriptions of imaginary animals and then attempted to classify novel verbal descriptions according to whether or not they fit the studied category. Controls exhibited good knowledge of the trained category, but amnesic patients did not. It is interesting to note that 5 of the 6 amnesic patients who participated in this study had also participated in our earlier study of category learning using dot patterns (Knowlton \& Squire, 1993), and all 6 patients had participated in our study of category learning using cartoon animals (Reed et al., 1999). In both studies, the amnesic patients exhibited robust category learning that matched the performance of controls.

The present study was based on the same cartoon animals used by Reed et al. (1999). In the latter study, participants learned by viewing pictures of 40 cartoon animals that were constructed with nine discrete features, and either seven or eight of the nine features were assigned the prototypic value. In the present study, each animal could vary with respect to eight discrete features, and training items were read to participants as 80 two-feature statements. Across the training phase each feature was assigned the prototypic value $75 \%$ of the time.

Despite these similarities between the present study and the earlier one, amnesic patients exhibited good category learning when pictures of animals were presented for training (Reed et al., 1999) but did not exhibit category learning when training consisted of reading aloud verbal descriptions of animals. The failure of amnesic patients to acquire category knowledge when the training items were presented verbally suggests that category learning in this case depended on the ability to extract meanings from multiple separate utterances and on the ability to retain these meanings explicitly.

There are a number of differences between those cases where amnesic patients have succeeded at category learning (dot patterns: Knowlton \& Squire, 1993; Squire \& Knowlton, 1995; artificial grammar learning: Knowlton \& Squire, 1994; cartoon animals: Reed et al., 1999) and the present case where they failed. Perhaps most important was the presentation of related visual stimuli in the studies where category learning succeeded and the presentation of verbal material in the present study. In the case of dot patterns and cartoon animals, the similarity among items is obvious at once, and amnesic patients may be able to extract invariance from the items as they encounter them. In the present study, similarity across items could be appreciated only by understanding the meaning of each item and then comparing and contrasting among items across trials. Thus, with verbal material, each spoken item may need to be retained in memory long enough for the common elements to be identified across trials and for a common theme to be constructed. If so, this feat would be beyond the capacity of amnesic patients.

In a series of studies, Schacter and his colleagues demonstrated impaired gist memory in amnesic patients when testing occurred in a recognition format. Especially when controls were prone to endorse unstudied items that resembled the set of training items (gist-based false recognition), amnesic patients exhibited less false recognition than controls. That is, they were not as likely as controls to endorse nonstudied prototypes as having been encountered previously (Koustaal, Schacter, Verfaellie, Brenner, \& Jack- son, 1999; Schacter, Verfaellie, \& Anes, 1997; Schacter, Verfaellie, Anes, \& Racine, 1998; Schacter, Verfaellie, \& Pradere, 1996).

In those studies of gist-based false recognition, amnesic patients apparently did not retain enough information about the study items to make the errors of false recognition that controls were prone to make. Similarly, in the present study, amnesic patients did not appear to be able to retain the specific-item information that was necessary to develop category knowledge.

Koustaal et al. (1999) found amnesic patients to exhibit less gist-based false recognition than controls, even when the stimulus materials were abstract designs presented visually. Three different categories were trained concurrently in the study, and the maximum number of items presented in any one category was nine. One possibility is that amnesic patients would perform as well as controls if they were instructed to classify new items rather than to recognize. Another possibility is that category learning proceeds best in amnesia when a single category is trained, when the study items are visually very similar (as in dot patterns), or when a large number of training items are used (as in dot patterns or cartoon animals). These conditions should discourage a memorizing (declarative) strategy in the controls and would seem favorable for successful category learning by amnesic patients. If so, the kind of instruction given (i.e., to recognize or to categorize) may be less important than the structure of the set of study items and the structure of the set of test items. Some evidence in favor of this idea comes from studies of category learning with dot patterns (Squire \& Zola, 1996, Figure 6, compare Panels A and B).

The present study establishes limits on the category learning ability of amnesic patients and, by extension, on what can be accomplished by nondeclarative memory. As has been pointed out previously (Cohen \& Eichenbaum, 1993; Packard \& McGaugh, 1996; Reed \& Squire, 1999; Squire, 1992), what is important is not the logical structure of the task but the strategy that is used to learn the task. Which strategy will be used can be expected to be influenced by many factors, including the instructions, the number of training trials, the nature of the material, the intertrial interval, and other aspects of the task structure.

\section{References}

Cohen, N. J., \& Eichenbaum, H. (1993). Memory, amnesia, and the hippocampal system. Cambridge, MA: MIT Press.

Knowlton, B. J., \& Squire, L. R. (1993). The learning of categories: Parallel brain systems for item memory and category knowledge. Science, 262, 1747-1749.

Knowlton, B. J., \& Squire, L. R. (1994). The information acquired during artificial grammar learning. Journal of Experimental Psychology: Learning, Memory and Cognition, 20, 79-91.

Koustaal, W., Schacter, D. L., Verfaellie, M., Brenner, C., \& Jackson, E. M. (1999). Perceptually-based false recognition of novel objects in amnesia: Effects of category size and similarity to category prototypes. Cognitive Neuropsychology, 16, 317-341.

Kritchevsky, M., Squire, L. R., \& Zouzounis, J. A. (1988). Transient global amnesia: Characterization of anterograde and retrograde amnesia. Neurology, 38, 213-219.

Osterreith, P. A. (1944). Le test de copie d'une figure complexe [Test of copying a complex figure]. Archives de Psychologie, 30, 206-256

Packard, M. G., \& McGaugh, J. L. (1996). Inactivation of hippocampus or caudate nucleus with lidocaine differentially affects expression of place and response learning. Neurobiology of Learning and Memory, 65, $65-72$. 
Palmeri, T. J., \& Flanery, M. A. (1999). Learning about categories in the absence of training: Profound amnesia and the relationship between perceptual categorization and recognition memory. Psychological Science, 10, 526-530.

Polich, J., \& Squire, L. R. (1993). P300 from amnesic patients with bilateral hippocampal lesions. EEG Clinical Neuropsychology, 86, 408417.

Reed, J. M., \& Squire, L. R. (1998). Retrograde amnesia for facts and events: Findings from four new cases. Journal of Neuroscience, 18 , 3943-3954.

Reed, J. M., \& Squire, L. R. (1999). Impaired transverse patterning in human amnesia is a special case of impaired memory for two-choice discrimination tasks. Behavioral Neuroscience, 113, 3-9.

Reed, J. M., Squire, L. R., Smith, E., Jonides, J., \& Patalano, A. (1999). Learning about categories that are defined by object-like stimuli in the absence of declarative memory. Behavioral Neuroscience, 113, 411419.

Rey, A. (1964). L'examen clinique psychologie [The clinical psychology exam]. Paris: Presses Universitaires de France.

Schacter, D. L., Chiu, C. Y., \& Ochsner, K. N. (1993). Implicit memory: A selective review. Annual Review of Neuroscience, 16, 159-182.

Schacter, D. L., \& Tulving, E. (Eds.). (1994). Memory systems, 1994. Cambridge, MA: MIT Press

Schacter, D. L., Verfaellie, M., \& Anes, M. D. (1997). Illusory memories in amnesic patients: Conceptual and perceptual false recognition. Neuropsychology, 11, 331-342.

Schacter, D. L., Verfaellie, M., Anes, M. D., \& Racine, C. (1998). When true recognition suppresses false recognition: Evidence from amnesic patients. Journal of Cognitive Neuroscience, 10, 668-679.
Schacter, D. L., Verfaellie, M., \& Pradere, D. (1996). The neuropsychology of memory illusions: False recall and recognition in amnesic patients. Journal of Memory and Language, 35, 319-334.

Shimamura, A. P., Jernigan, T. L., \& Squire, L. R. (1988). Korsakoff's Syndrome: Radiological (CT) findings and neuropsychological correlates. Journal of Neuroscience, 8, 4400-4410.

Squire, L. R. (1992). Memory and the hippocampus: A synthesis from findings with rats, monkeys, and humans. Psychological Review, 99, 195-231.

Squire, L. R., Amaral, D. G., \& Press, G. A. (1990). Magnetic resonance measurements of hippocampal formation and mamillary nuclei distinguish medial temporal lobe and diencephalic amnesia. Journal of Neuroscience, 10, 3106-3117.

Squire, L. R., \& Knowlton, B. J. (1995). Learning about categories in the absence of memory. Proceedings of the National Academy of Sciences, USA, 92, 12470-12474.

Squire, L. R., \& Shimamura, A. P. (1986). Characterizing amnesic patients for neurobehavioral study. Behavioral Neuroscience, 100, 866-877.

Squire, L. R., \& Zola, S. M. (1996). Structure and function of declarative and nondeclarative memory systems. Proceedings of the National Academy of Sciences, USA, 93, 13515-13522.

Warrington, E. K. (1984). Recognition Memory Test. Windsor, England: NFER Nelson.

Received July 12, 1999

Revision received December 9, 1999

Accepted April 13, 2000

\section{Low Publication Prices for APA Members and Affiliates}

Keeping you up-to-date. All APA Fellows, Members, Associates, and Student Affiliates receive-as part of their annual dues-subscriptions to the American Psychologist and APA Monitor. High School Teacher and International Affiliates receive subscriptions to the APA Monitor, and they may subscribe to the American Psychologist at a significantly reduced rate. In addition, all Members and Student Affiliates are eligible for savings of up to $60 \%$ (plus a journal credit) on all other APA journals, as well as significant discounts on subscriptions from cooperating societies and publishers (e.g., the American Association for Counseling and Development, Academic Press, and Human Sciences Press).

Essential resources. APA members and affiliates receive special rates for purchases of APA books, including the Publication Manual of the American Psychological Association, and on dozens of new topical books each year.

Other benefits of membership. Membership in APA also provides eligibility for competitive insurance plans, continuing education programs, reduced APA convention fees, and specialty divisions.

More information. Write to American Psychological Association, Membership Services, 750 First Street, NE, Washington, DC 20002-4242. 